\title{
The Key Drivers to Setting up a Valuable and Sustainable HOF Approach in a High-Risk Company such as Airbus
}

\author{
Florence Reuzeau
}

\begin{abstract}
Airbus has been investing in developing human and organizational factors (HOF) approaches for the last three decades. With hindsight, we can identify and capitalize on the key drivers for setting up a valuable and sustainable HOF approach in a high-risk company such as Airbus. These drivers can be the role of regulators, the standardization and visibility of HOF approaches within the company, HOF governance and competence management. However, there is no room for complacency in a competitive market with regards to sustaining HOF approaches at the appropriate level. Therefore, the message should be to define and measure what can be described as HOF maturity indicators to be integrated into the company dashboard.
\end{abstract}

Keywords Human factors · Organizational factors $\cdot$ Standards $\cdot$ Competences • Governance $\cdot$ Maturity

\section{Introduction}

The development of human and organizational factors (HOF) approaches in a large group depends on very different factors such as the expected benefits, obligations (certification), induced cost and organizational structure of the company. In Airbus, there are two endemic issues: human factors and organizational factors.

The first issue relates to the human factors (HF) at workstation for the workers (or blue-collars) in the plants as well as for the human operators of an aircraft: reducing the effect of working conditions on the Health and Safety of human operators, enhancing the safety of air transportation, supporting the introduction of new technologies, machines, tools, or new operational procedures. Productivity and cost reduction are part of the equation, as are cost of design, industrialization and enduser training. Whatever the domain of application, the key challenge today and for the future is to understand and anticipate how human operators can behave and will

\footnotetext{
F. Reuzeau $(\bowtie)$

Airbus, Toulouse, France

e-mail: florence.reuzeau@airbus.com

(C) The Author(s) 2020

B. Journé et al. (eds.), Human and Organisational Factors,

SpringerBriefs in Safety Management,

https://doi.org/10.1007/978-3-030-25639-5_5
} 
behave in their daily operations. This is particularly challenging for the aircraft product as they are designed to be used for around 40 years, meaning there will be two or three generations of multi-cultural human operators. Disciplines such as psychology, ergonomics, sociology, linguistics and neuroscience are fully integrated into the company to cope with these aspects.

The second issue relates to organizational factors (OF). Airbus is an international company whose research, development, production and customer services activities are distributed in Europe and around the world. How can international organizations, processes, methods and tools be conceived to be usable by any employee in order to design, produce and deliver the order backlog, taking safety, security and profitability into account? In addition, company performance is subject to the performance of the whole extended enterprise, the suppliers and the subcontractors. Moreover, there is some internal testing of new organizational ways of working such as liberated enterprise, agile methodology, remote work. It is very difficult in such an organization to differentiate the implications of individual versus collective factors on the work.

Management sciences, psychologists and sociologists from Human Resources are supporting these actions in a transnational mode. It is quite a new phenomenon compared to the introduction of human sciences in the human factors field.

\section{History, Looking Back}

Airbus historically invested in HOF approaches in industrial production mainly for Health \& Safety considerations. In 1984, the first "ergonomics department" was set up in the manufacturing organization to develop "work analysis" as a key methodology for supporting the introduction of new and novel machines, tools, product lines and new buildings. This included working organization, job instructions, training, etc. In 1993, the decision was made to allocate one ergonomist position per plant and assembly line to support management decision-making. The great diversity of human factors issues (physical ergonomics, cognitive ergonomics, health, mixed workers generation, competences, robots/cobots, and new technologies like augmented reality, etc.) and the chasing of human-induced non-quality make this job quite challenging. Today, the company is engaged in the digital transformation through the factory of the future. Airbus mandated an ergonomist coordinator to gather and share best practices among the facilities distributed in Europe.

In 1988, the Airbus Training Center was also provided with a small team of people with human factors competences in charge of developing and deploying teaching techniques and working with instructors to define training policies (in line with the Crew Resource Management courses).

Early 1990s, it was decided to set up a new HF organization for supporting the commercial aircraft design process, with the objectives of enhancing safety and customer efficiency. Although this evolution was first initiated by an Airbus employee, it must be situated in the context of an epoch for aviation and human science. In 1996, the US authorities launched a worldwide review of HF integration in the 
aeronautical domain, where the FAA (Federal Aviation Administration) called on very well-known and legitimate HF scientists. Following statistical analyses of commercial accidents and incidents, human errors were identified, and continue to be identified, as a first-rate causal factor [4]. At the same time, it had become obvious that the human sciences could not only offer an explanatory assessment of aviation accidents but could also provide a positive contribution in aircraft design and operations. This resulted in the definition of a first lever for an efficient HOF approach: the role of regulators.

\section{The Role of Regulators: Pushing Safety Requirements and HOF Induction}

The first lever driving considerations of human factors in product certification was the "strong recommendation" from the FAA to use "at the edge human science knowledge". This shared awareness between industries, academics and regulators gradually led to an evolution of the certification texts. This initiative was part of a time of formalization and dissemination of human science knowledge in a way usable by the industry. Of course, a series of ergonomics criteria, automation and computerization considerations [3] already existed but spread across various documents [2]. The first ISO 13407 (Human centered design process for interactive systems) was issued in 1999 before being extended to ISO 9241 [6] which incorporated a huge number of relevant requirements and guidance to support a "User centered design" approach. Standards and regulations are today available to regulate new aircraft projects (ARP 5056 [1], CS 25-1302, RTCA SC-233). They define safety standards and set out strong recommendations for demonstrating compliance to regulations. Beyond the HF criteria, compliance also recommends setting up a HF process throughout the design and certification phases.

The regulators elaborate requirements on OF matters too. We cannot avoid mentioning a very important process that contributes to ensuring aviation safety: the SMS (Safety Management System). It is defined as: "a systematic, explicit and comprehensive process for managing safety risks". As a global risk management system, the Safety Management System provides for goal setting, planning, measuring performance and proposing action for improvement.

\section{Standard HF Processes in Aircraft Design Engineering}

Airbus fully defined and integrated its own "HF design \& certification process" [8]. It is based on the adaptation of 9241-11 to Airbus context. Today it is considered to be a mature process for addressing the current human challenges. The Airbus Human Factors Design Process (HFDP) is a set of activities at system and aircraft 
level that defines (1) the human operators' tasks and needs; (2) the HF issues and benefits related to human(s)-machine interaction; (3) the expected performance of the human-machine; (4) the validation plan to demonstrate the expected performance of the human-machine. It can be done through analysis or simulation with end-users in the loop using a scenario-based approach; and finally demonstrating compliance with HF certification. The HF process application is led by HF specialists who work in an integrated team (end users, designers, HF) for the duration of a technical project.

Regulations do not only govern design, but also flight operations, procedures, pilot training, maintenance operations, simulator qualification in the form of the "Operational Suitability Data" (OSD) mandating that aircraft manufacturers, who have to submit data to EASA, consider important for safe operations.

As with the other Airbus processes, standardization is key and can be considered as a second lever towards long-term change in the industry.

The Airbus HFDP is part of the other engineering processes along with quality, safety, and validation processes. The Airbus design office numbers several thousands of engineers worldwide and even more when encompassing the extended enterprise perimeter. Standardized HF process, requirements and guidelines (such as a Cockpit Philosophy) and shared HF evaluation methods are contributing factors for developing a consistent cockpit and cabin product whatever the diversity of design teams or the diversity of profiles, culture, experiences and job assignment in the supply chain. Why is it so important to define a standard process? Because a repetitive process, independent from any specific context, is more likely to change the internal way of working. It allows a comprehensive application of the process without having to negotiate the conditions on a case by case basis.

Other industries developed or are currently developing their own HF process. In 2010, a group of industries coming from ground, air and naval transportation, powerplant and government bodies shared their best practices through a series of workshops under the AFIS umbrella [5]. AFIS stands for the French Association of System Engineering. Eurocontrol has also created a common HF process to steer Air Navigation Service Providers to develop and deploy the new Air Traffic Management solutions, for increasing traffic capacity in a consistent manner (Human Performance Assessment Process) as described in Pelchen-Medwed and Biede-Straussberger [7].

\section{HOF: Governance and Organization}

The third lever is HF governance. Engineering and customer services top management mandated in 2015 a HF board to ensure proper decision-making and follow up on HF activities. The HF board is a decision-making authority and is composed of top managers and high-level human factors experts. The top managers cover the functions for which human factors can highly impact aircraft safety, the health and safety of workers or the global efficiency of Airbus product for customers. Safety management needs a global consideration of human factors. It includes the definition of a clear, unified HOF strategy, policies and priorities for all Airbus products and 
processes (aircraft, documentation, training, maintenance, etc.). The board allows $\mathrm{HOF}$ to be considered as a cross-functional discipline across organizations. Aircraft safety, flight testing, systems design, industrial quality, aircraft programs, architecture and customer services are discussing how to establish a consistent philosophy on implementing and disseminating HOF throughout the aircraft cycle. For example, if an in-flight event that occurred in service is classified as human factors, it is analysed from the design and the operational point of view with a consistent model of human behavior. The HF board is key for assessing, explaining, analysing, and predicting the impact of HOF in political, economic and safety-related scenarios and decisions.

This decision board helps to promote the visibility and the legitimacy of human factors in the company. It reinforces the recognition and the authority of HF through the involvement of top managers. It is also a way to share and coordinate crossorganizations.

In term of implementing HF in the business, Airbus decided to organize HF in a decentralized manner. It means that several HF specialist teams are located near to their respective centres of competence. For instance, one HF organization is located in the cockpit design centre of competence, another one is in the cabin domain. Highlevel experts oversee technical coordination. A network of human factors specialists has been set up to allow any HF specialist to know and exchange with any HF colleague within Airbus overall.

On the production side, a similar network was organized as a real asset to cope with the specific difficulties of this sector. Unlike in the engineering environment, the ergonomics specialists are spread across the European plants and Final Assembly Lines (FAL) and can feel as if they are working in isolation from other HF specialists. Promoting networking inside a HF community is a favorable condition for HOF performance.

Poor ergonomics in manual handling operations are identified as the second most common cause of long-term injuries in the Airbus production sector. MusculoSkeletal-Disorder (MSD) is the most common cause of absence with a significantly high number of days lost per year, as has been the case for many years. This awareness led to the implementation of a network of dedicated ergonomists working in all production plants across Europe.

The network is also covering the Final Assembly Lines (FAL). A central coordinator is in charge of managing the network, sharing best practices amongst the facilities and defining the strategy for ergonomics in production. One of the results is a common document of aligned rules, which are derived from international standards, national obligations and specific requirements in terms of ergonomics with respect to Health \& Safety. They are applicable to all plants, FAL, and also provided when a new line design is subcontracted to suppliers. Based on the key indicator methods (holding, lifting, carrying, pulling, pushing) ergonomic conditions and MSD relevant activities are screened and anticipated.

Countermeasures are taken to correct the past and also prevent for the future.

Even when manual handling operations of loads and associated postures do not completely cover the full set of ergonomics, it is essential to interact at an early stage, referring to the known number of injuries. 
Beside of these ergonomics considerations, workstation design on the shop floor is also influenced by different environmental factors i.e. organization (time), logistics (tasks and flows) and interaction (human-machine).

This becomes important whenever ergonomic analyses are made, especially when investigating alternative scenarios, working with collaborative robots, smart tools etc.

In order to get full integrity, we are aiming to achieve valuable ergonomic conditions across the chain of Engineering, Manufacturing and Maintenance.

This will reduce the number of lost time injuries and increase the safety and quality of work and ultimately the health of employees. Furthermore, it is key for future production design, helping the company to be competitive and efficient.

Quite recently and after a long period of "independence", the different HF organizations (engineering, customer services and production) moved closer in order to exchange on topics such as "human and robots", smart tools, cognitive assistants and the use of big data to better understand actual human operator behavior. The improved connection between Engineering and Manufacturing is not specific to HF, it is part of the 'factory of the future' project to better consider the manufacturability requirements in the design so as to reduce the lead time and cost of operations. HF should be involved at the appropriate level for the benefits of the workers and work organization.

One of our most important projects is now to collectively review the current HOF to face the future challenges as new concepts of operations (Reduced team operations, factory of the future, remote control room...) and new kind of technologies associated with increased automation, augmented intelligence systems, robots/cobots...Consequently, new HF competences, new ways of working and new standards need to be invented.

\section{HOF Competence Management}

The fourth lever is competence management. In-service event analysis shows that Runway Excursion, Loss of Control, and Control Flight Into Terrain are persistent events. Human error is often cited as a primary cause or contributing factor in most accidents. It means that we need to reinforce HF education in the aviation community: HF related to approach and landing management, energy management, attention allocation, crew fatigue, manual flying following automation degradation, or procedure management are just examples. As such, the competencies implemented to apply the HF approach are a combination of human sciences (cognitive psychology, linguistics, physiology, human-machine interaction, sociology), operational knowledge (pilots, cabin crew, etc.) and engineering skills. Airbus decided to recruit these specialists.

HF specialists are always a small group of people among thousands of engineers. They can be considered as "cost/time constraint" and of course as troublemakers when challenging the "expected human behaviors' assumptions" of the engineering staff. As a minority, human factors specialists should always demonstrate their added value in front of a "monocultural engineering world". Educating a large number of 
engineers and managers in HF should help to reinforce the efficiency of a multidisciplinary team, but it is costly. The aviation industry is helped by a series of initiatives that disseminate human science knowledge. For example, Yeh et al. [10] issued a report on human factors considerations in the design and evaluation of flight deck displays and controls. For its part, Airbus is currently developing a set of rich media and a knowledge pack using the company intranet and low-cost dissemination tools. Nevertheless, we are investing in HF experts and their career path. These experts are an asset for the company. They have a strong academic background in the most relevant human science disciplines and have acquired much on the job experience. They work together and are responsible for the development of HF competences in their centre of competences. They are known by the management and responsible for elaborating the vision in their domain of expertise.

But we can ask ourselves how to develop a stronger footprint, looking at how the "User eXperience (UX) design" community has rapidly won new markets. UX design is a process of designing (digital or physical) products that are useful, easy to use and, above all, a pleasure to interact with. It is about making sure the end users find a hedonic value in the usage of the product. Even if UX design studies have a direct impact on sale and revenue as they are directly impacting the "mass buyer" whereas HOF in industry is generally impacting the employee performance, and rather a source of cost and not a direct source of revenue. But let us be creative to offer the best product to the end users, integrating the conventional HF qualitative values and hedonic values in a same HF label.

\section{Conclusion, HOF Maturity}

Regardless of our efforts, these four levers cannot be enough to guarantee the success of the HOF approach in the future.

New technological developments and economic changes offer a large number of opportunities but also important challenges for organizations. Among these evolutions, autonomous transportation, connectivity, IOT (Internet Of Things), robotics and artificial intelligence will have a huge impact on human life as well as on human operators at work.

Staying aligned with the strategic objectives and preparing the future is paramount for companies. The previous levers for implementing HF standard processes, HF governance, and competence management are the critical ingredients of a HOF maturity framework to guarantee that:

- the projects deliver as expected,

- the projects selected are the ones that support the company strategy and bring the best benefits: selection of the most critical projects with a high added value. For example, the selection should include the "burning" projects, the ones that solve important issues in daily operations as well as the project that drive the research strategy, 
- the teams have the appropriate knowledge, process, methods and tools,

- the HOF organization has the necessary capacity to continuously anticipate the evolutions (adaptability, change mindset),

- the HOF organization is sustainable and robust. It is independent enough from the human factors specialists in charge of HOF.

A suggestion would be to measure HOF maturity on a regular basis to identify and understand what is useful or not so useful, or to identify how to achieve a higher level of maturity.

This is key to setting up a valuable and sustainable HF approach.

The level of maturity should define the "predictability, effectiveness, and control of the HOF". HF governance allows the improvement process, that is the highest level of maturity. We could summarize the HOF maturity level in the Fig. 1.

The model provides a theoretical continuum along which process maturity can be developed incrementally from one level to the next. Skipping levels is not allowed/feasible.

As a conclusion, we may recommend setting up efficient HOF approaches. First of all, to integrate the HF processes into the current/existing business organizational model of the company processes, with the same level and the same visibility compared to other processes. Second, to set up HF governance at the higher level of management to share the risks of not having an appropriate HOF approach and define the suitable $\mathrm{HF}$ strategy. And third to elaborate relevant indicators to measure the maturity level of $\mathrm{HOF}$ and to monitor it on a regular basis to ensure optimal consideration of HOF. These fundamentals should allow us to shape the significant changes we see

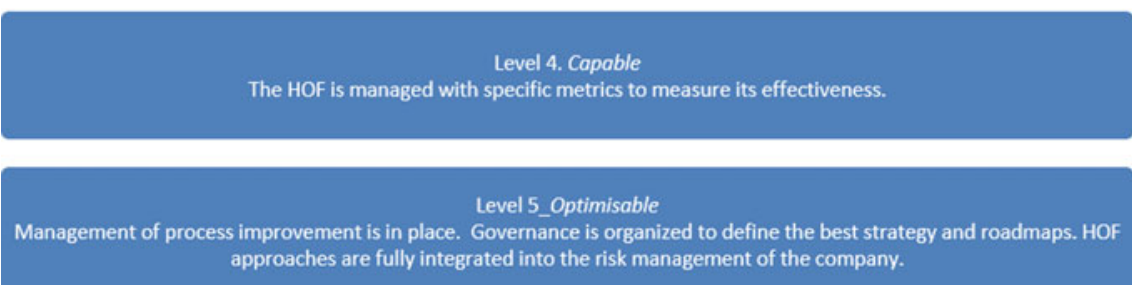

Fig. 1 Level of HOF maturity [adapted from integration of the test maturity model (TMMi [9])] 
as robotics increase (between 1993 and 2007, robot density increased by more than $150 \%$ ) or digitalization expands without overly penalizing the working conditions of human operators.

This is crucial for a business that must adapt to new market challenges and customer expectations.

\section{References}

1. ARP5056, Flight crew interface considerations in the flight deck design process for part 25 aircraft. SAE 2006-07-05 (n.d.), https://www.sae.org/standards/content/arp5056/

2. L. Bannon, Issues in design. Some notes, in User-Centered System Design, ed. by D.A. Normal, S.W. Draper (Lawrence Erlbaum Associates, 1986), pp. 25-29

3. C.W. Billings, in Aviation Automation: The Search for a Human-Centered Approach (Lawrence Erlbaum Associates, 1997)

4. FAA human factors team, The interfaces between flight crews and modern flight deck systems. FAA report (1996)

5. E. Gardinetti, D. Soler, F. Reuzeau, C. Maïs, X. Chalandon, Ingénierie des facteurs humains, in ERGO IA2014, Biarritz, October 2014

6. ISO 9241-210, Ergonomics of human-system interaction—Part 210: human-centred design for interactive systems (2010)

7. R. Pelchen-Medwed, S. Biede-Straussberger, Effectiveness of the application of the HP assessment process in SESAR1, in USA/Europe ATM Seminar/Seattle, 26-30 June 2017

8. F. Reuzeau, Human factors design process: benefits and success factors, in 3rd Human Dependability Workshop (HUDEP 2013), ESA. Munich, 13 \& 14 November 2013

9. TMMi, Test maturity model integration, (the TMMi Model). TMMi Foundation (n.d.), https:// www.tmmi.org/tmmi-model/

10. M. Yeh, J. Young, C. Donovan, S. Gabree, Human factors considerations in the design and evaluation of flight deck displays and controls. Version 1.0 final report-November 2013 DOT/FAA/TC-13/44 (2013)

Open Access This chapter is licensed under the terms of the Creative Commons Attribution 4.0 International License (http://creativecommons.org/licenses/by/4.0/), which permits use, sharing, adaptation, distribution and reproduction in any medium or format, as long as you give appropriate credit to the original author(s) and the source, provide a link to the Creative Commons license and indicate if changes were made.

The images or other third party material in this chapter are included in the chapter's Creative Commons license, unless indicated otherwise in a credit line to the material. If material is not included in the chapter's Creative Commons license and your intended use is not permitted by statutory regulation or exceeds the permitted use, you will need to obtain permission directly from the copyright holder.

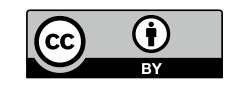

